\title{
Influence of nest burrow microclimate on chick growth in a colonial High-Arctic seabird, the little auk
}

\author{
Izabela Kulaszewicz (1) \& Dariusz Jakubas (D) \\ University of Gdańsk, Faculty of Biology, Department of Vertebrate Ecology and Zoology, Gdańsk, Poland
}

\begin{abstract}
The growth of seabird chicks is affected by various environmental conditions. Although species nesting in burrows may thereby reduce the effects of environmental conditions, they are still dependent on the nest microclimate. We investigated the influence of nest microclimate on chick growth in the little auk (Alle alle), a colonial High-Arctic seabird breeding in Hornsund (south-west Spitsbergen). We recorded air temperature inside and outside 10 active nests during two phases of breeding and during post-breeding period (no birds inside). We found that temperatures differed significantly among the nests. Air temperatures in nests located at higher altitudes were significantly higher, which can be attributed to the absorption of the Sun's rays at a higher angle, resulting in a greater heat flux. Nest chamber temperatures were significantly higher (by $0.46^{\circ} \mathrm{C}$ ) than ambient ones. During the post-breeding period, $24 \mathrm{hr}$ cycle nest temperatures were more stable than ambient temperatures, indicating the important insulating function of nest burrows. Little auk chicks grew faster in nests with higher mean temperatures. In the first phase of chick growth (15th to 18 th day of life), a $1{ }^{\circ} \mathrm{C}$ difference in the nest temperature resulted in differences in head-bill length and body mass growth of $0.80 \mathrm{~mm}$ and $0.76 \mathrm{~g}$ per day, respectively. Our study demonstrates the importance of the thermal nest environment in determining chick growth in a species breeding in harsh High-Arctic conditions.
\end{abstract}

\section{KEYWORDS}

Nest temperature; Svalbard; dovekie; Alle alle

\section{ABBREVIATIONS}

AGR: absolute growth rate; ANOVA: analysis of variance test; HBL: head-bill length

\section{Introduction}

Nesting in polar regions poses energy challenges to birds owing to low temperatures, high winds, short phenological windows for breeding and rapid environmental fluctuations. Meteorological conditions can affect growing offspring directly, especially in species whose chicks develop full thermoregulation only a few days after hatching (Erikstad \& Andersen 1983; Jørgensen \& Blix 1985; Krijgsveld et al. 2003; Tortosa \& Castro 2003), or indirectly by impairing the hunting ability of parental birds (Newton 1978; Taylor 1983). An appropriate egg temperature maintained by the incubating adult is thought to be crucial for the proper development of avian embryos (Webb 1987). It has been reported for a few species that prolonged exposure to cold reduces the rate of development (Tazawa et al. 1989), extends incubation phases (Lyon \& Montgomerie 1985) and may negatively influence post-hatch growth (Sockman \& Schwabl 1998). Changes in ambient temperature have previously been matched with variation in seabirds' breeding success (Konarzewski \& Taylor 1989; Jarvinen 1994; Sheaier \& Malecki 1996; Skinner et al. 1998). In order to maintain the temperature range optimal for chick development, birds must make up the heat lost from the clutch with an equivalent input of warmth (increased incubation effort). Therefore, the quality of the nest and its location are considered important factors reducing the energetic costs of chick rearing (Furness \& Bryant 1996). Many birds occupy nest sites with optimal exposure to the Sun (Walsberg \& King 1978). Other species use vegetation above the nest to shade it from too intense solar radiation (Schaaf et al. 2018). Insulation against ambient temperatures is typical for different kinds of natural cavities, situated in rock, ground or tree. Microclimates of cavity nests are generally less variable and harsh compared with exposed ground nests (Kesler \& Haig 2005; Mallory \& Forbes 2011; MerstenKatz et al. 2012, Maziarz \& Wesołowski 2013). Natural tree cavities are better insulated against ambient temperature than artificial nest-boxes (Maziarz et al. 2017).

Cooler nest microclimates may force chicks to invest more energy in thermoregulation at the expense of other metabolic processes, e.g., growing or immune function (Chappell et al. 1990; Visser 1998; Dawson et al. 2005). The effect of nest temperature on chicks' growth has been tested experimentally. The reduced nest temperature during incubation resulted in lower chick growth rate and reduced chick-rearing capacity in adults. Thus, environmental conditions and trade-offs experienced by embryos and parental birds during incubation can have important carry-over effects on later life-history stages (Nilsson et al. 2008; Ardia et al.

CONTACT Izabela Kulaszewicz bioik@univ.gda.pl D Department of Vertebrate Ecology and Zoology, University of Gdańsk, Wita Stwosza 59, 80-308, Gdańsk, Poland

(1) Supplemental data for this article can be accessed here. 
2010; Andreasson et al. 2018). Existing studies on this subject are mainly focused on species breeding in nestboxes or tree cavities in the temperate zone or on cavity nesters breeding in the tropics (McComb \& Noble 1981; Wiebe 2001). Natural tree cavities are more efficient thermal insulators compared to artificial nest-boxes, which provide poor insulation with negligible buffering against ambient temperatures (Maziarz et al. 2017). Only a few studies have been carried out on species breeding in polar regions characterized by a harsh environment with low ambient temperatures, high winds and a short summer (e.g., Manuwal 1974; Erikstad \& Andersen 1983; Steen \& Gabrielsen 1986; Konarzewski \& Taylor 1989). Some homoeothermic vertebrates function there at the lower limit of their thermoneutral zone (Konarzewski \& Taylor 1989).

The little auk (Alle alle), also known as the dovekie, is an endemic High-Arctic seabird breeding colonially in nest chambers under stones in rock scree or in rock crevices (Stempniewicz 2001). Its breeding is strictly governed by the springtime melting of snow and ice, which allows the birds to enter the burrows to nest. Little auks match their reproduction to the period when soil temperatures are above $0^{\circ} \mathrm{C}$ (Moe et al. 2009; Jakubas \& Wojczulanis-Jakubas 2011). The slopes occupied by little auk colonies generally consist of many subareas, varying in physical and social features such as micro-topography, vegetation, location on the slopes and breeding density (Jakubas \& Wojczulanis-Jakubas 2011). Particular breeding pairs may therefore experience in their nest burrows microclimatic conditions differing from those in the neighbouring burrows. In mid-June, the little auk lays a single egg, which is incubated by both sexes for 28 days (Stempniewicz 2001). The nestlings remain in the nest for four weeks before fledging; during this time they are fed with small planktonic crustaceans, predominantly copepods (Stempniewicz 2001). The chicks are brooded by parents for five to seven days until they achieve complete homeothermy (Gabrielsen et al. 1991).

In this study, we investigated inter-nest differences in nest air temperature and the influence of burrow nest microclimate on little auk chick growth. Considering micro-scale differences (within one colony patch) in nest location (altitude, slope), we hypothesized that the inside air temperature varies between nest burrows. We also expected that the microclimate of each nest would differ from ambient conditions, i.e., the air temperature inside the nest would be higher than the ambient temperature. Moreover, we expected that during the $24 \mathrm{hr}$ cycle nest air temperatures would be more stable than ambient temperatures. Given reported positive influence of nest burrow temperature on chick growth ratio (e.g., Dawson et al. 2005), we expected that chicks from nests with a colder microclimate would develop more slowly because of the higher energy expenditure on thermoregulation. Assuming that older and more experienced adults may start breeding earlier by choosing better (warmer) nests (e.g., De Forest \& Gaston 1996; Pyle et al. 2001), we expected that chicks would hatch earlier in nests with higher air temperatures.

\section{Methods}

\section{Fieldwork}

We conducted the study in a large patch (estimated at 128 breeding pairs [Keslinka et al. unpubl. data]) of the little auk colony in Hornsund, a fjord in south-west Spitsbergen, at $77^{\circ} 00^{\prime} \mathrm{N} 15^{\circ} 33^{\prime} \mathrm{E}$, in 2015 . Hornsund is considered one of the largest breeding aggregations of little auks in Svalbard (Isaksen 1995) and serves as a representative sample for the larger Spitsbergen population. To study nest microclimate, we selected 10 nests with interiors of bare rock (no additional insulation material, only small pebbles on the bottom of nest chamber) located under stones in scree. We selected a uniform patch of the colony, ca. $100 \mathrm{~m}^{2}$ in size, with a slope of $25-35^{\circ}$ at altitudes from $35 \mathrm{~m}$ to $80 \mathrm{~m}$ a.s.l. The patch had the same south-eastern exposure throughout. Nest chambers had a maximum depth of $0.4 \mathrm{~m}$. We chose nests with a similar depth to exclude the effect of depth as a variable influencing the temperature inside the nest. The permafrost probably has a cooling effect but we assume that it is similar all across the study area. The active status of each nest was confirmed by the presence of an egg during incubation. We measured the altitude of each nest (Garmin 64st, with a barometer sensor, accurate to $3 \mathrm{~m}$ ). To record nest burrow air temperature (hereafter nest temperature), we placed three iButton temperature loggers (model DS1921Z-F5, Maxim Integrated Products; accurate to $0.125^{\circ} \mathrm{C}$; working in range from $-5^{\circ} \mathrm{C}$ to $+26^{\circ} \mathrm{C}$ ) inside each nest, each at different distances from the entrance: at the bottom of the nest; $0.1 \mathrm{~m}$ above the bottom on the side walls and under a rock that covers the nest burrow (Supplementary Fig. S1). Outside the nest chamber, we inserted a stick with a temperature logger placed $0.2 \mathrm{~m}$ aboveground for recording ambient temperature (shielded from the solar radiation by a wooden cover at the top and sides). All the data loggers were programmed for recording temperature during three days per session at 10 minute intervals, and all of them recorded data at the same time.

We measured temperatures from 10 July to 27 August, a time span covering the following phenological periods. The first was chick rearing, which had two phases representing the main stages of little auk growth: phase 1, 30 July-2 August, when chicks were 15-18 days old and were in the linear growth phase (Konarzewski \& Taylor 1989); phase 2, 5-8 August, when chicks were 21-24 days old and were in the body mass recession phase (Konarzewski \& Taylor 1989; Stempniewicz 2001). We used these data to 
examine the relationship between nest temperature and chick growth. The second phenological period was post-breeding (25-27 August), when we measured raw nest temperatures period, after the young had fledged, to exclude the thermal effect of the birds' presence inside the nest chamber. We did not measure temperature in the early phase of chick rearing so as to minimize disturbance and reduce the risk of nest abandonment.

\section{Chick growth parameters}

To study chick growth, we selected a group of 10 nests for which the hatching dates were known with temperature loggers inside that had been installed two days before hatching. We inspected the nests every day starting from five days before the expected hatching date (based on data from previous seasons) until recorded hatching date. To avoid disturbing the birds, we did not monitor the nests during the first two weeks after hatching. Then, we captured, ringed and measured the chicks on the 15th day of their lives (since recorded hatching date) from all the nests for the first time. Subsequently, to track chick growth, we weighed and measured them at three-day intervals until fledging. We measured HBL (measured from the tip of bill to the back of the base of skull with callipers accurate to $0.01 \mathrm{~mm}$ ) and body mass (with an electronic balance accurate to $0.1 \mathrm{~g}$ ).

To describe chick growth, we used the AGR (Richards 1959; Hunt 1990): $A G R=\left(W_{2}-W_{1}\right) /\left(t_{2}-t_{1}\right)$, where $W_{1}$ and $\mathrm{W}_{2}$ are variables (HBL and chick body mass) measured at times $t_{1}$ and $t_{2}$.

We calculated AGR for the body mass in two important phases of little auk chick growth (Konarzewski \& Taylor 1989): AGR1 for phase 1 of chick rearing, i.e., linear growth between the 15th day of life and peak body mass (phase 1: 15th to 18th day of life, 30 July2 August); AGR2 for phase 2 (body mass recession) between the day of peak body mass and fledging (21st to 24th day of life, 5-8 August). The first phase represents the stage of maximum energy demand of growing chicks after they have achieved independent thermoregulation (at seven days).

\section{Data analysis}

To investigate inter-nest differences in nest air temperatures, we used random effects ANOVA, separately for the two phases of chick growth with nest temperature records as the dependent variable, nest ID as predictor and two random factors (temperature logger ID and day). In this analysis for each nest we considered in total 1296 temperature values per one nest (representing six measurements per hour during three consecutive days by three loggers). We used Student $t$-tests for paired samples to compare the differences between nest temperatures and ambient temperatures. For each nest we considered in total 432 temperature values (representing mean values from three loggers recording six measurements per hour during three consecutive days) and corresponding 432 values from the ambient temperature logger (representing mean values from one logger recording six measurements per hour during three consecutive days).

We investigated the relationship between altitude and mean nest temperature using Pearson's correlation coefficient separately for the following three sets of data: (1) to evaluate the impact of temperature on chick growth, we investigated the relationship between mean nest temperature and the relative chick growth rate during the two chick-rearing phases (AGR1 and AGR2); (2) to explore the relationship between differences in nest temperature between the two chick-rearing phases and chick growth ratios; (3) to investigate whether earlier breeders (usually considered to be more experienced, high-quality individuals [Weimerskirch 1992]) had chosen warmer nests, we examined the relationship between mean nest temperature and chick hatching dates (Julian dates). To analyse these relationships we used one temperature value per each nest, representing mean daily temperatures from three consecutive days from the three locations in a burrow. We used a quadratic function to show the relationships (this type of function was better fitted to data than a linear function).

To investigate whether nest temperatures were more stable than ambient temperatures, we compared the daily distributions of nest and ambient temperatures during the post-breeding period. We chose the postbreeding period to exclude the thermal effect of the birds' presence inside the nest chamber. We compared mean nest and ambient temperatures per hour in the $24 \mathrm{hr}$ cycle (mean from values measured by three sensors during three consecutive days with a sampling rate of 10 minutes) using the Kolmogorov-Smirnov test for equal distribution with a Monte Carlo permutation.

To compare "night" and "day" temperatures we performed separate Student $t$-tests for nest and ambient temperatures during the post-breeding period. We also compared "day" and "night" temperatures between nest and ambient loggers using Student's $t$-test for dependent samples. "Night" hours were taken to be 20:00-03:50, when the colony was shaded by the mountain; "day" hours were 04:00-19:50. For visualization of temperature differences in nests located at different heights we presented daily diagrams for selected nest burrows from different heights above sea level.

We used a Q-Q plot and Levene's test to assess whether the data met the assumptions of the linear model. Before correlation analyses, we Box-Cox transformed the temperatures (Osborne 2010). We performed a Kolmogorov-Smirnov test for equal distribution with a Monte Carlo permutation in PAST 3.20 (Hammer et al. 2005) and all other statistical analyses in Statistica 10 (StatSoft, Inc.). We set the significance level to $p<0.05$. 


\section{Results}

\section{Nest microclimate during the chick-rearing period}

We found that nest temperature differed significantly between the majority of the little auk burrows in both phase 1 (mean $\pm \mathrm{SE}$ inter-nest difference: $1.28 \pm 0.27^{\circ} \mathrm{C}$; random effects ANOVA, $F_{10,12} 955=225.35, p<0.001$, $N=12960$ ) and phase 2 (mean \pm SE: $1.67 \pm 0.29^{\circ} \mathrm{C}$; random effects ANOVA, $F_{10,12} 955=251.44, p<0.001$, $N=12960$ ) of chick rearing (Figs. 1,2). The effect of sensor ID, the random factor, was significant (random effects ANOVA, phase 1: ANOVA, $F_{10,12} 955=101.5$, $p=0.006$; phase 2: ANOVA, $F_{10,12} 955=132.13$, $p=0.004, N=12960)$. The effect of the second random factor, day, was insignificant (random effects ANOVA, phase 1: ANOVA, $F_{10,12955}=65.8, p=0.098$; phase 2: ANOVA, $\left.F_{10,12} 955=78.9, p=0.112, N=12960\right)$.

Our analyses revealed that nests situated at a higher altitude had a higher mean temperature in both chickrearing phases (Pearson's correlation coefficient, phase 1: $r_{10}=0.75, p<0.001$, phase 2: $r_{10}=0.68, p<0.001$, Fig. 3 ).

\section{Nest microclimate during the post-breeding period}

We found that the little auk nest temperatures varied significantly (on average by $1.5^{\circ} \mathrm{C}$ ) in the majority of the burrows during the post-breeding period (random effects ANOVA, $F_{10,12} 955=132.9, p<0.001, N$ $=12$ 960; Fig. 1, Table 1). The effect of sensor ID, the random factor, was significant (random effects ANOVA, $F_{10,12} 955=89.3, p=0.007, N=12960$ ). The effect of the second random factor, day, was not significant (random effects ANOVA, $F_{10,12} 955=35.9$, $p=0.075, N=12960$ ).

Our analyses demonstrated that the burrow temperature was significantly higher than the ambient temperature measured outside the nest (paired samples Student $t$-tests, Table 2, Figs. 4,5 ) and that mean nest temperature increased with altitude (Pearson's correlation coefficient, $r_{10}=0.86, p<0.005, N=10$; Fig. 3).

\section{Distribution of daily nest and ambient temperatures}

We found the daily distribution of nest and ambient temperatures to differ significantly during the postbreeding period (Kolmogorov-Smirnov test with a Monte Carlo permutation, $\mathrm{D}=0.387, p=0.041$; Table 2, Fig. 5). Nest temperatures were more stable $\left(\mathrm{SD}=0.50^{\circ} \mathrm{C}\right.$, minimum-maximum: $0.36-0.75^{\circ} \mathrm{C}$ ) than ambient temperatures $\left(\mathrm{SD}=1.36^{\circ} \mathrm{C}\right.$, minimummaximum $=1.12-1.81^{\circ} \mathrm{C}$; Fig. 5). During the postbreeding period, mean "day" ambient temperatures were significantly higher (by $2.55^{\circ} \mathrm{C}$ ) than "night" ambient temperatures (Student $t$-test, $t_{4319}=32.35, p<0.01$, $N=4320$; Table 3 ). In contrast, both "day" and "night" temperatures were similar in most nests (Student $t$-test, $t_{12956}=12.56, p=0.105$; Table 3). Mean "night" temperatures in nests were significantly higher (by $1.37^{\circ} \mathrm{C}$ )

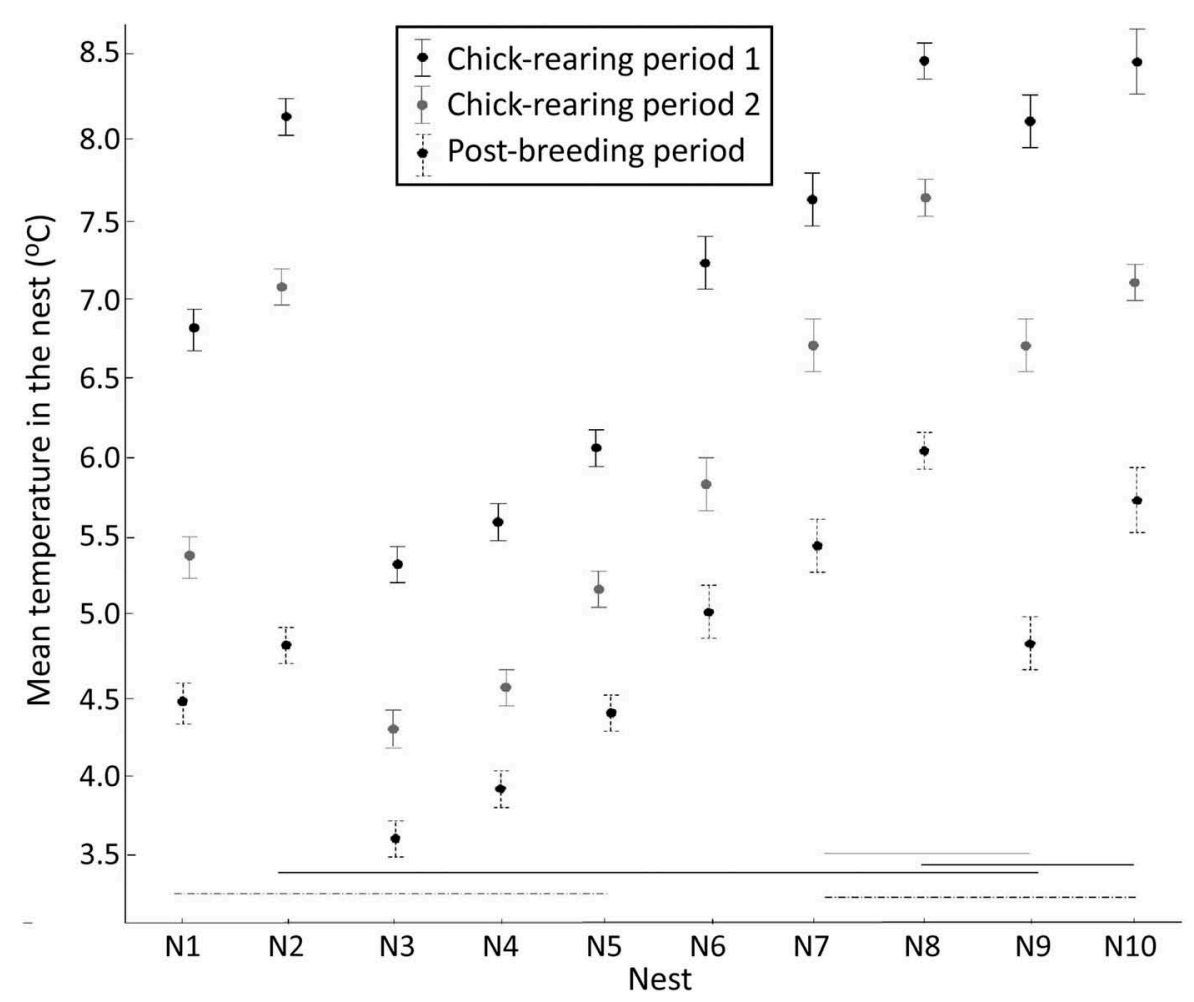

Figure 1. Nest temperatures (mean $\pm \mathrm{SE}$ ) in phase 1 (20 July-2 August) and phase 2 (5-8 August) of the chick-rearing period, and during the post-breeding period (25-27 August). All inter-nest differences are significant (random effects ANOVA, $p>0.05$, $N=1296$ temperature records for each nest; separate analyses for particular phases), except for those shown by horizontal lines. 


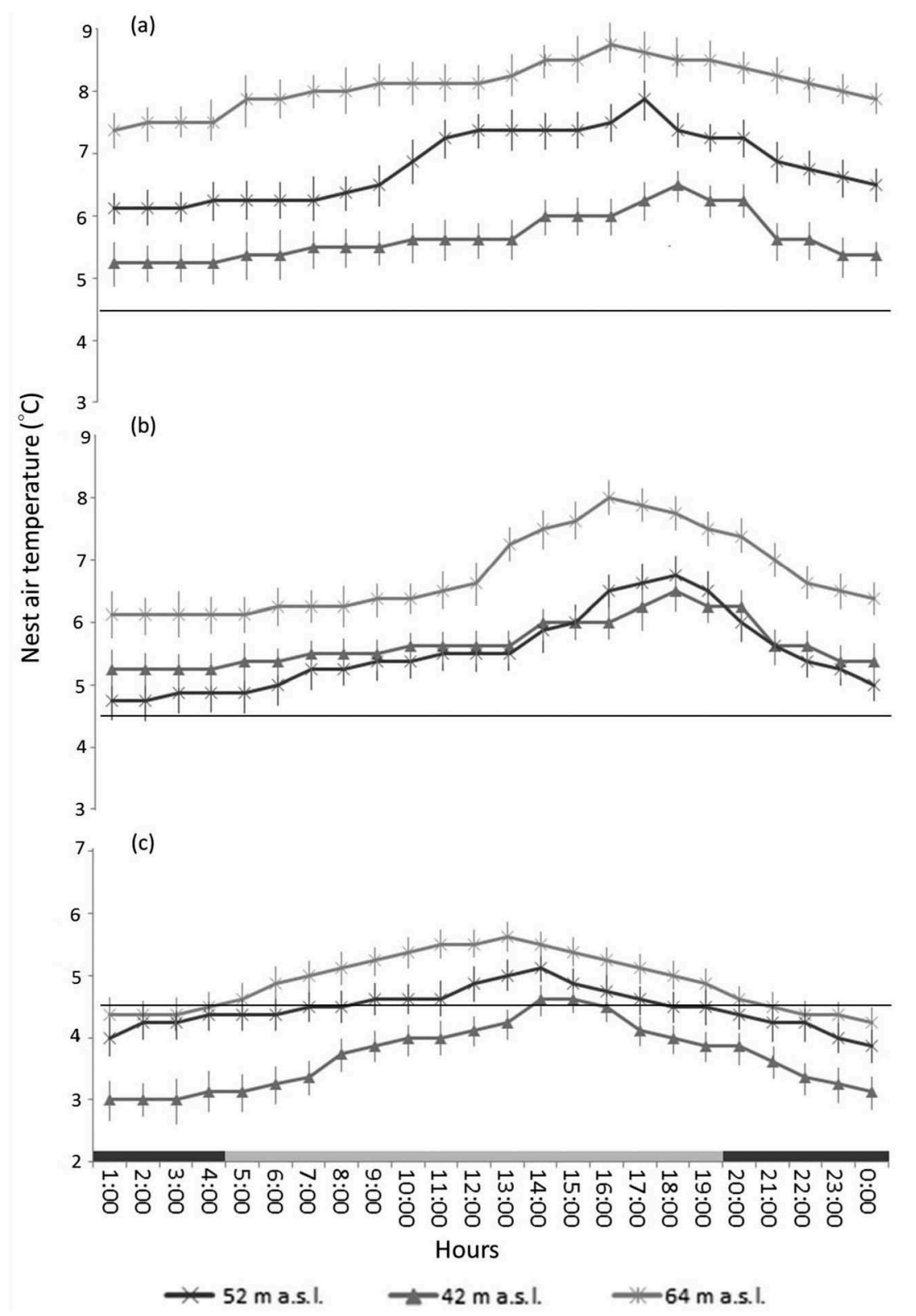

Figure 2. Mean \pm SD nest temperatures in the $24 \mathrm{hr}$ cycle (mean value from three loggers for a three-day period) in three nests (different altitude) in (a) phase 1 (20 July-2 August), (b) phase 2 (5-8 August) of chick rearing and (c) during the post-breeding period (25-27 August). The thermoneutral zone of little auks $\left(4.5^{\circ} \mathrm{C}\right.$; Gabrielsen et al. 1991) is shown by the horizontal black line. The "day" and "night" hours are shown at the bottom of the graph by the horizontal light and dark grey bars, respectively.

than ambient ones (Student $t$-test for dependent samples, $\left.t_{1439}=24.16, p=0.016, N=1440\right)$. Mean "day" nest temperatures were lower (by $0.84^{\circ} \mathrm{C}$ ) than ambient ones (Student $t$-test for dependent samples, $t_{2879}=11.89$, $p=0.039, N=2880)$.

\section{Influence of nest microclimate on chick growth}

We found that AGR of HBL in little auk chicks were higher in nests with higher mean nest temperatures in both phase 1 (Pearson's correlation coefficient, $\left.\beta=0.78, \mathrm{R}^{2}=0.64, p<0.005, N=10\right)$ and phase $2\left(\beta=0.68, \mathrm{R}^{2}=0.46, p<0.005, N=10\right)$ (Fig. 6). AGR1 of chick body mass was positively correlated with mean nest temperature in phase 1 (Pearson's correlation coefficient, $\beta=0.73, \mathrm{R}^{2}=0.68$, $p<0.001, N=10$; Fig. 6). However, we found no significant relationship for AGR2 of body mass and temperature in phase $2\left(\beta=0.25, \mathrm{R}^{2}=0.16\right.$, $p=0.35, N=10$; Fig. 6). During the first phase of chick growth (15th to 18 th day of life), a $1^{\circ} \mathrm{C}$ difference in nest temperature resulted in a difference in $\mathrm{HBL}$ and body mass growth of $0.81 \mathrm{~mm}$ and $0.77 \mathrm{~g}$ per day, respectively. During the second phase, a $1^{\circ} \mathrm{C}$ difference in nest temperature resulted in a difference in body mass growth of $0.67 \mathrm{~g}$ per day.

We did not find a significant relationship between chick hatching date and the mean nest temperature in either phase 1 (Pearson's correlation coefficient, $\beta=0.52, p=0.43, N=10)$ or phase $2(\beta=0.06$, $p=0.54, N=10)$. 


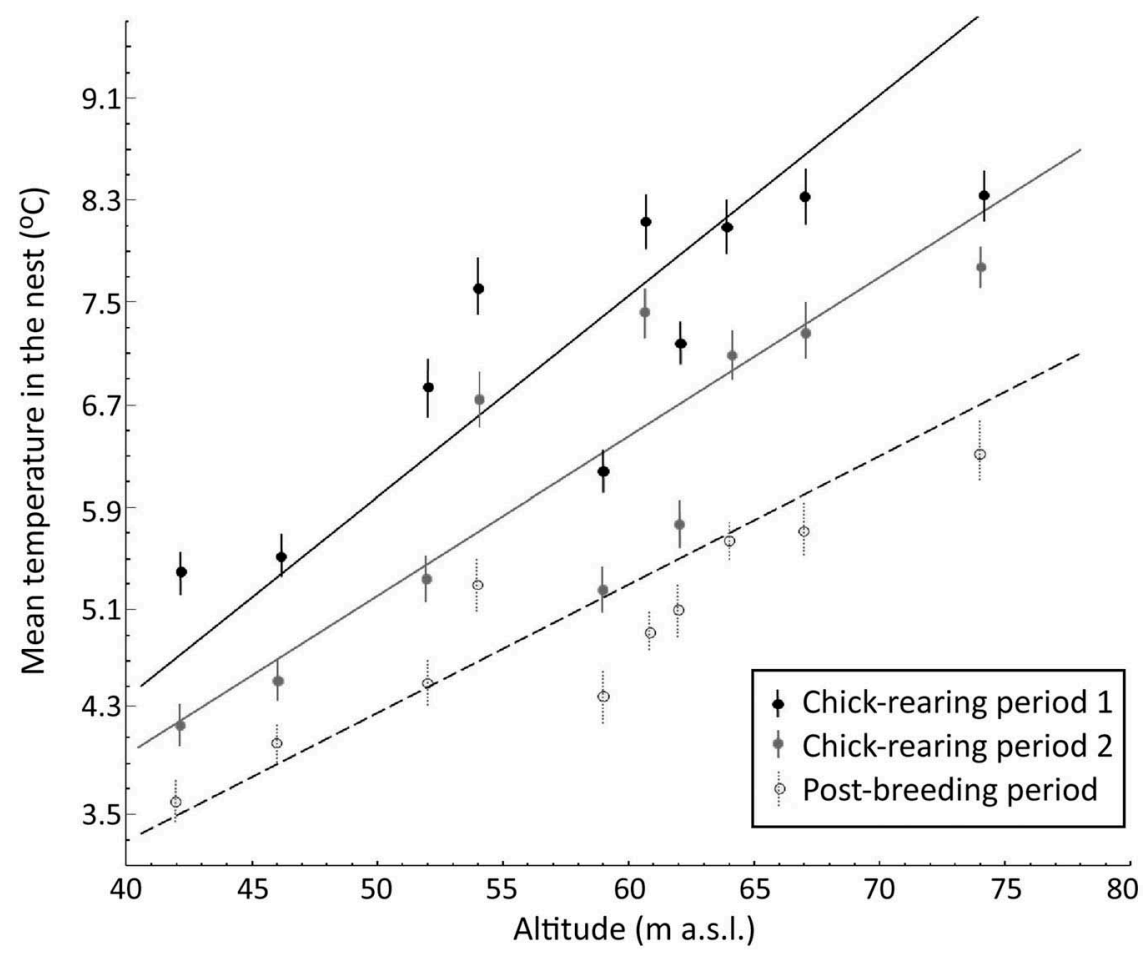

Figure 3. Relationship between nest temperature (mean $\pm S D$, mean daily temperatures calculated from the three locations in a burrow during consecutive three days) and altitude in nests during two chick-rearing phases and the post-breeding period. Regression lines are shown for significant relationships.

Table 1. Nest and ambient temperatures (mean $\pm \mathrm{SE}$ ) during the post-breeding period (25-27 August), results of paired sample $t$-tests for each nest with its altitude, and the difference between ambient and nest temperatures. Significant differences $(p<0.05)$ are shown in boldface.

\begin{tabular}{|c|c|c|c|c|c|c|c|}
\hline \multirow[b]{3}{*}{ Nest ID } & \multirow{3}{*}{$\frac{\text { Altitude }}{\text { (m a.s.l.) }}$} & \multirow{3}{*}{$\frac{\text { Nest }}{\text { temperature }\left({ }^{\circ} \mathrm{C}\right)}$} & \multirow{3}{*}{$\frac{\text { Ambient }}{\text { temperature }\left({ }^{\circ} \mathrm{C}\right)}$} & \multirow{3}{*}{$\frac{\text { Temperature }}{\text { difference }\left({ }^{\circ} \mathrm{C}\right)}$} & \multirow{2}{*}{\multicolumn{3}{|c|}{$\begin{array}{c}\text { Paired samples t-tests } \\
\text { Nest vs Ambient }\end{array}$}} \\
\hline & & & & & & & \\
\hline & & & & & $\mathrm{df}$ & $t$ & $p$ \\
\hline N1 & 52 & $4.48 \pm 0.043$ & $3.92 \pm 0.073$ & -0.56 & 431 & -6.15 & $<0.001$ \\
\hline N2 & 61 & $4.82 \pm 0.028$ & $4.19 \pm 0.084$ & -0.63 & 431 & -10.08 & $<0.001$ \\
\hline N3 & 42 & $3.71 \pm 0.042$ & $3.55 \pm 0.061$ & -0.16 & 431 & 3.33 & 0.11 \\
\hline N4 & 46 & $3.96 \pm 0.032$ & $3.90 \pm 0.054$ & -0.06 & 431 & 1.98 & 0.09 \\
\hline N5 & 59 & $4.41 \pm 0.008$ & $4.14 \pm 0.092$ & -0.27 & 431 & 1.15 & 0.004 \\
\hline N6 & 62 & $5.01 \pm 0.077$ & $4.68 \pm 0.068$ & -0.33 & 431 & -12.87 & 0.011 \\
\hline N7 & 54 & $5.42 \pm 0.040$ & $4.86 \pm 0.048$ & -0.56 & 431 & -17.43 & $<0.001$ \\
\hline N8 & 74 & $6.27 \pm 0.085$ & $5.77 \pm 0.063$ & -0.50 & 431 & -12.33 & $<0.001$ \\
\hline N9 & 64 & $4.88 \pm 0.026$ & $4.28 \pm 0.073$ & -0.60 & 431 & -15.94 & $<0.001$ \\
\hline N10 & 67 & $5.88 \pm 0.052$ & $5.30 \pm 0.077$ & -0.58 & 431 & -15.33 & $<0.001$ \\
\hline All nests combined & & $4.84 \pm 0.092$ & $4.02 \pm 0.094$ & $-0.43 \pm 0.08$ & 4319 & -27.32 & $<0.001$ \\
\hline
\end{tabular}

We found that the difference in the little auk nest temperatures between the two chick-rearing phases did not affect AGRs in either phase 1 (Pearson's correlation coefficient, body mass: $r_{10}=0.24, p=0.26$; HBL: $r_{10}=0.16, p=0.33$ ) or phase 2 (body mass: $r_{10}=0.19$, $p=0.57$; HBL: $r_{10}=0.21, p=0.26$ ).

\section{Discussion}

We found micro-scale variation in the mean temperature of little auk nests in all the phases investigated. These were most likely due to differences in nest altitude. Nests located at higher altitudes can absorb the Sun's rays at a higher angle, which results in a greater heat flux, even at the microscale (Vermeer et al. 1979; Walsberg 1981). The temperatures of the nests studied here fell steadily with decreasing amounts of solar energy delivered. We can assume that the warmest nests during chick rearing were also the warmest during incubation. However, the hatching date was not significantly related to the thermal characteristics of the nests during chick rearing. This may suggest that differences in nest temperatures did not affect hatching dates. Significant differences in hatching dates in little auks have been noted on a broader scale, among sub-colonies differing considerably in aspect, slope and altitude (Jakubas \& Wojczulanis-Jakubas 2011). 
Table 2. Comparisons of $24 \mathrm{hr}$ distributions of nest and ambient temperatures. Student $t$-tests comparing the difference between "night" and "day" ambient and nest temperatures during the post-breeding period (24 hr cycle, 25-27 August). Significant differences $(p<0.05)$ are in boldface.

\begin{tabular}{|c|c|c|c|c|c|c|c|c|c|c|}
\hline \multirow[b]{3}{*}{ Nest ID } & & & & & \multicolumn{6}{|c|}{$\begin{array}{r}\text { Comparison of "day" vs "night" temperatures (Student } \\
t \text {-tests) }\end{array}$} \\
\hline & \multicolumn{4}{|c|}{$\begin{array}{l}\text { Altitude } 24 \mathrm{~h} \text { distribution of nest vs ambient temperatures } \\
\qquad\left(\mathrm{K}-\mathrm{S} \text { test }^{\mathrm{a}}\right)\end{array}$} & \multicolumn{3}{|c|}{ Ambient temperatures } & \multicolumn{3}{|c|}{ Nest temperatures } \\
\hline & (m a.s.l.) & df & $\mathrm{D}$ & $p$ & df & $t$ & $p$ & df & $t$ & $p$ \\
\hline N1 & 52 & 431 & 0.198 & 0.211 & 431 & 34.54 & 0.032 & 1295 & 8.72 & 0.091 \\
\hline $\mathrm{N} 2$ & 61 & 431 & 0.598 & 0.034 & 431 & 54.32 & 0.021 & 1295 & 9.14 & 0.166 \\
\hline N3 & 42 & 431 & 0.134 & 0.245 & 431 & 44.16 & 0.027 & 1295 & 11.21 & 0.089 \\
\hline N4 & 46 & 431 & 0.242 & 0.152 & 431 & 27.67 & 0.045 & 1295 & 7.76 & 0.176 \\
\hline N5 & 59 & 431 & 0.692 & 0.038 & 431 & 65.44 & 0.011 & 1295 & 14.45 & 0.056 \\
\hline N6 & 62 & 431 & 0.789 & 0.001 & 431 & 58.65 & 0.019 & 1295 & 15.64 & 0.059 \\
\hline N7 & 54 & 431 & 0.287 & 0.167 & 431 & 55.11 & 0.022 & 1295 & 11.26 & 0.092 \\
\hline N8 & 74 & 431 & 0.754 & 0.011 & 431 & 67.12 & 0.015 & 1295 & 19.78 & 0.047 \\
\hline N9 & 64 & 431 & 0.684 & 0.034 & 431 & 39.15 & 0.016 & 1295 & 12.98 & 0.083 \\
\hline N10 & 67 & 431 & 0.722 & 0.022 & 431 & 48.76 & 0.025 & 1295 & 17.16 & 0.044 \\
\hline All nest combined & & 4309 & 0.432 & 0.047 & 4309 & 32.18 & $<0.001$ & 12959 & 12.56 & 0.105 \\
\hline
\end{tabular}

${ }^{a}$ Kolmogorov-Smirnov test comparing distributions of mean hour nest and ambient temperatures.

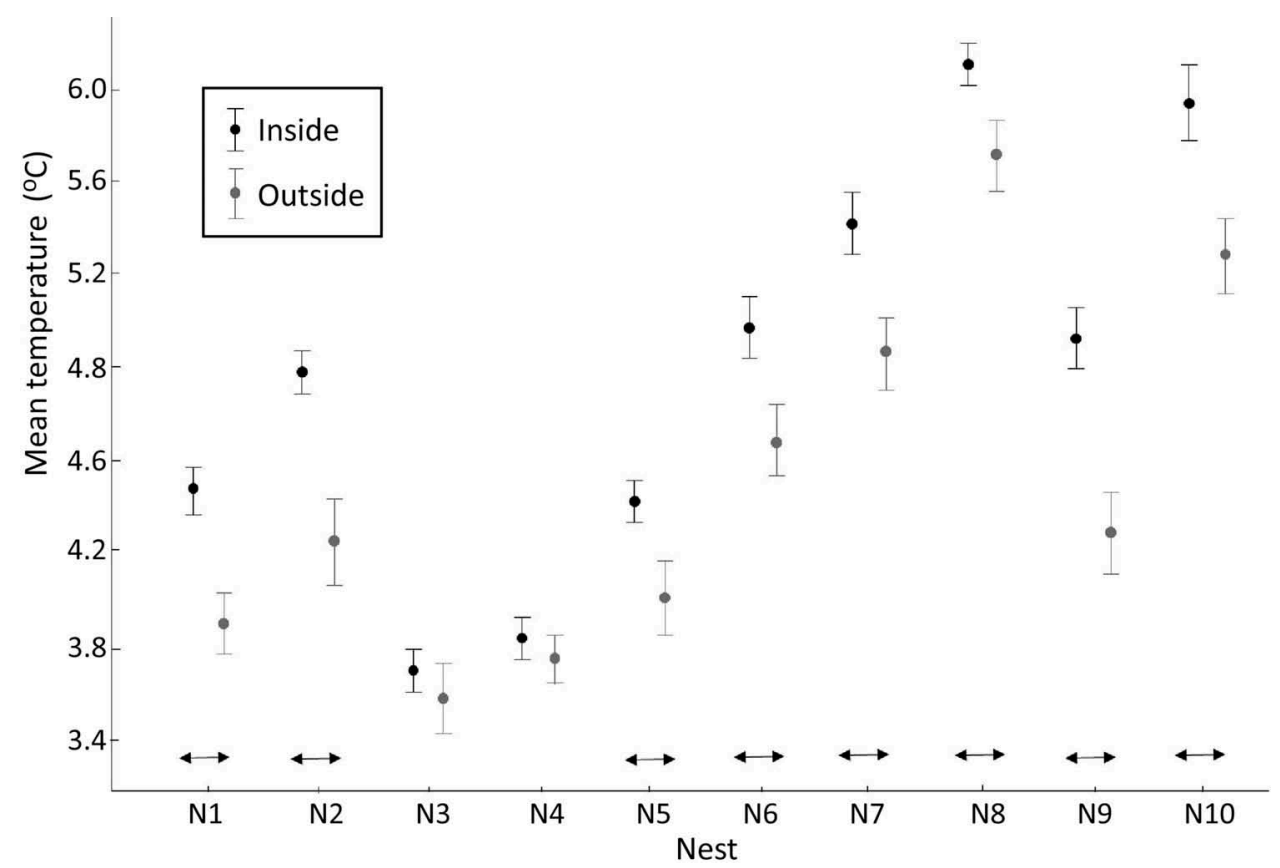

Figure 4. Temperature inside nests and ambient (outside) temperature (mean \pm SE) during the post-breeding period (2527 August). The arrows indicate significant differences between nests and ambient temperatures for particular burrows (paired samples $t$-tests, $p<0.05, N=432$ ).

As we predicted, temperatures inside the little auk nests studied were higher than outside, even when the birds were no longer present in them (post-breeding period). In the Cassin's auklet (Ptychoramphus aleuticus), another burrow-nesting alcid, nest temperatures were never lower than the mean ambient temperature (Manuwal 1974). It could be argued that the $0.5^{\circ} \mathrm{C}$ difference between nest and ambient temperatures found in our study, despite being statistically significant, is negligible from a biological point of view. However, it is well to recall that little auks breeding in the High Arctic operate close to lower limit of their thermoneutral zone $\left(4.5^{\circ} \mathrm{C}\right.$; Gabrielsen et al. 1991). Even a small difference in temperature may have a considerable impact on their breeding performance or chick growth.

The distributions of daily nest and ambient temperatures during the post-breeding period differed in the majority of the nests analysed (Table 3). Ambient temperatures in the "night" hours in midnight Sun conditions were lower than during the "day" hours because of the shading effect of the mountain. During the $24 \mathrm{hr}$ cycle nest temperatures were more stable than ambient temperatures, which is indicative of the important insulating function of nest burrows.

Our study found that the AGR for HBL in little auk chicks during both phases of growth was faster in nests with higher mean temperatures. The quicker body size 


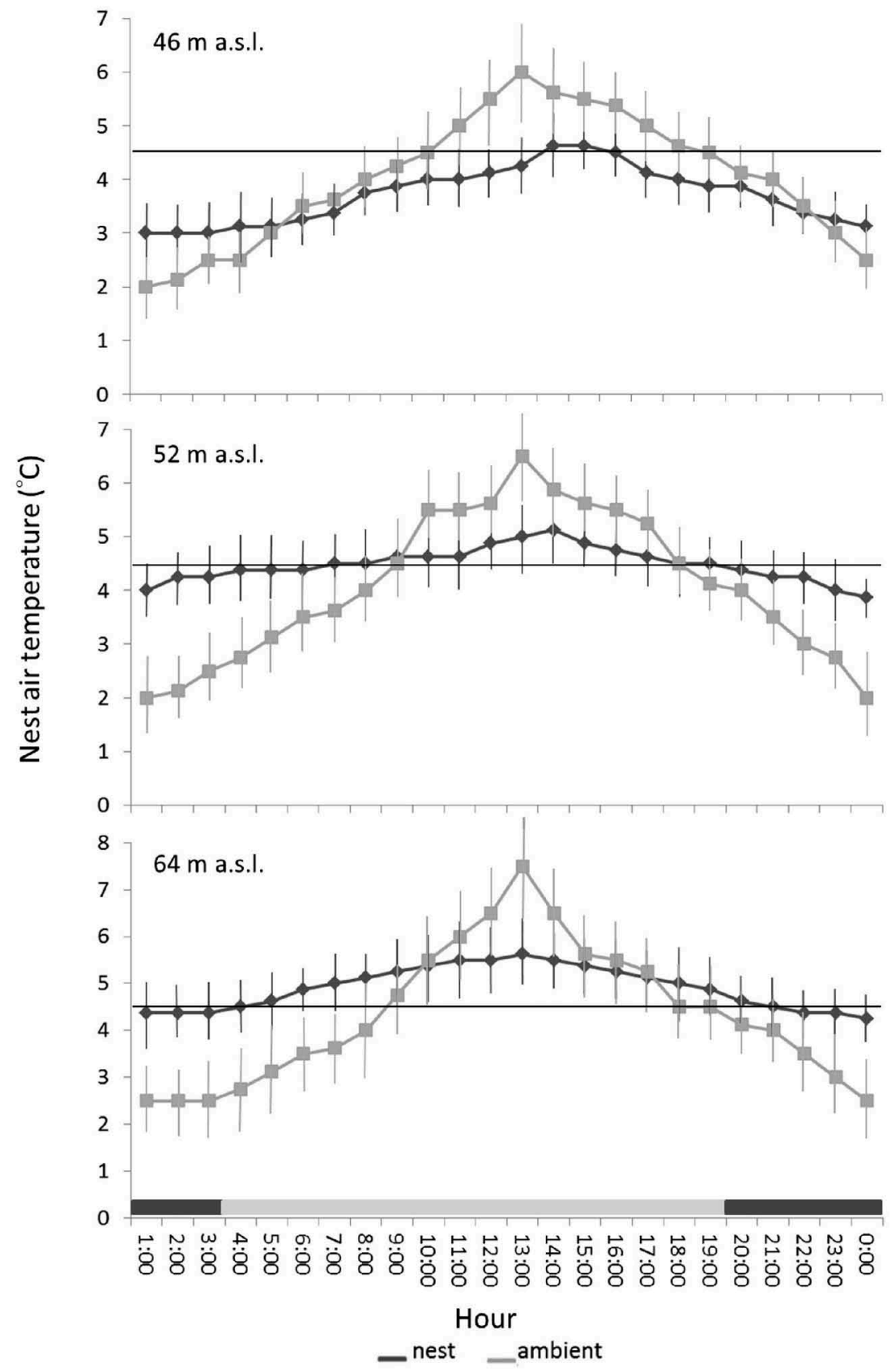

Figure 5. The mean \pm SD nest and ambient temperatures in the $24 \mathrm{hr}$ cycle in three nests (different altitude) during the postbreeding period (25-27 August). The thermoneutral zone of little auks (4.5 ${ }^{\circ} \mathrm{C}$; Gabrielsen et al. 1991) is shown by a horizontal black line. The "day" and "night" hours are shown at the bottom of the graph by the horizontal light and dark grey bars, respectively.

growth rate may enhance post-fledging survival in seabirds (Kersten \& Brenninkmeijer 1995; Morrison et al. 2009). Also, AGR1 for body mass was higher in nests with higher mean temperatures. A similar pattern was found in ground-nesting Adélie penguins (Pygoscelis adeliae), where embryo development and chick growth rates increased with increasing incubation temperatures (Derksen 1977). In the Wilson's storm petrel (Oceanites oceanicus), too, a high correlation between air temperature and increases in weight of chicks was reported (Wasilewski 1986). The body mass of little auk offspring may vary among sub-colonies as an effect of nest microclimate (Jakubas \& Wojczulanis-Jakubas 2011). The lack of a significant correlation between
AGR2 and mean nest temperature may be due to the recession in chick body mass prior to fledging. This mass at fledgling, and consequently AGR2, may not be as closely linked to post-fledging survival in little auks, which fledge at only $67-82 \%$ of adult body mass (Stempniewicz 2001). In addition, previous studies of little auks did not report a significant correlation between nest temperature and body mass (Konarzewski \& Taylor 1989). In contrast, high precipitation had a negative influence on growth rate and fat deposits in little auk chicks (Konarzewski \& Taylor 1989).

In conclusion, our study indicates that even slight differences in nest temperature may affect significantly chick growth in a High-Arctic seabird, 

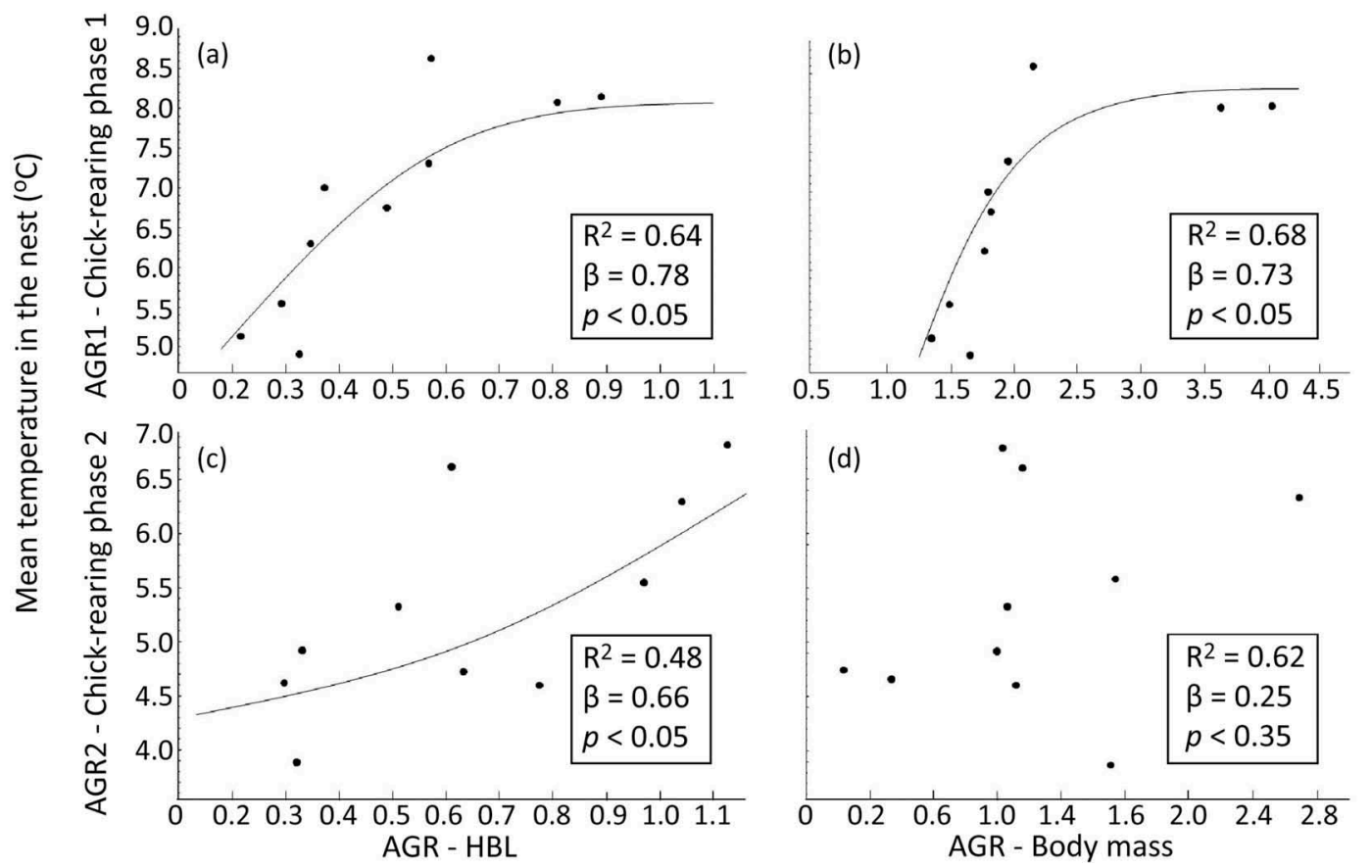

Figure 6. Relationship between mean nest temperatures in phase 1 (30 July-2 August) and phase 2 (5-8 August) of the chickrearing period and the AGR of little auk chicks (AGR1 and AGR2) based on (a, c) HBL and (b, d) body mass. Regression lines are shown for significant relationships.

the little auk. In the first phase of chick growth (15th to 18 th day of life), a $1{ }^{\circ} \mathrm{C}$ difference in nest temperature resulted in a difference in HBL and body mass growth of $0.8 \mathrm{~mm}$ and $0.76 \mathrm{~g}$ per day, respectively. We found that nest temperature is influenced by its micro-scale location in terms of altitude-driven differences in microclimate. Hence, burrow nesters, especially those breeding in harsh conditions with temperatures close to the lower limit of their thermoneutral zone, should select for nest sites well insulated against adverse temperatures, thereby providing optimal conditions for offspring growth.

We are aware that our study has limitations. We did not control chick growth for parental provisioning quality or quantity. However, as it took place in one season in a small colony patch, we assumed that chick provisioning quality and quantity as well as parental bird quality (reflected by the lack of inter-nest differences in hatching dates) were similar in all the nests we surveyed. Further studies based on larger samples, including various seasons differing in trophic conditions and/or various patches of colony differing in slope and exposure are needed. Nevertheless, our study has filled an evident information gap about the influence of nest microclimate on chick growth of species breeding in harsh environmental conditions. A recent experimental study demonstrated that heat transmission to the egg during incubation may be an important constraint on clutch size in the little auk (Jakubas \& Wojczulanis-Jakubas 2014). A comprehensive study to investigate microclimatic conditions in nests that covers all phases of breeding should lead to a greater understanding of the constraints on breeding performance in low-fecundity birds.

\section{Acknowledgements}

All the fieldwork was done by permission of the Norwegian Animal Research Committee and the Governor of Svalbard. We appreciate the improvements to our English as suggested by Peter Senn and the reviewers.

\section{Disclosure statement}

No potential conflict of interest was reported by the authors.

\section{Funding}

The study was supported by a grant from the National Science Centre (Preludium 5; UMO-2013/09/N/NZ8/ 03208) and by a grant from the University of Gdańsk (538-L120-B930-15).

\section{ORCID}

Izabela Kulaszewicz (D) http://orcid.org/0000-0002-33201875

Dariusz Jakubas (D) http://orcid.org/0000-0002-1879-4342

\section{References}

Andreasson F., Nord A. \& Nilsson J.-Å. 2018. Experimentally increased nest temperature affects body temperature, 
growth and apparent survival in blue tit nestlings. Journal of Avian Biology 49, UNSP e01620, doi:10.1111/jav.01620.

Ardia D.R., Pérez J.H. \& Clotfelter E.D. 2010. Experimental cooling during incubation leads to reduced innate immunity and body condition in nestling tree swallows. Proceedings of the Royal Society of London B: Biological Sciences 277, 1881-1888.

Chappell M.A., Morgan K.R. \& Bucher T.L. 1990. Weather, microclimate, and energy costs of thermoregulation for breeding Adélie penguins. Oecologia 83, 420-426.

Dawson R.D., Lawrie C.C. \& O'Brien E.L. 2005. The importance of microclimate variation in determining size, growth and survival of avian offspring: experimental evidence from a cavity nesting passerine. Oecologia 144, 499-507.

De Forest L.N. \& Gaston A.J. 1996. The effect of age on timing of breeding and reproductive success in the thick-billed murre. Ecology 77, 1501-1511.

Derksen D.V. 1977. A quantitative analysis of the incubation behavior of the Adélie penguin. The Auk 94, 552-566.

Erikstad K.E. \& Andersen R. 1983. The effect of weather on survival, growth rate and feeding time in different sized willow grouse broods. Ornis Scandinavica 14, 249-252.

Furness R.W. \& Bryant D.M. 1996. Effect of wind on field metabolic rates of breeding northern fulmars. Ecology 77, 1181-1188.

Gabrielsen G.W., Taylor J.R., Konarzewski M. \& Mehlum F. 1991. Field and laboratory metabolism and thermoregulation in dovekies (Alle alle). The Auk 108, 71-78.

Hammer Ø., Harper D. \& Ryan P.D. 2005. PAST: paleontological statistics software package for education and data analysis. Palaeontologica Electronica 4, article no. 4.

Hunt R. 1990. Absolute growth rates. In R. Hunt (ed.): Basic growth analysis. Pp. 17-24. Dordrecht: Springer.

Isaksen K. 1995. The breeding population of little auk (Alle alle) in colonies in Hornsund and northwestern Spitsbergen. K. Isaksen \& V. Bakken (eds.): Seabird population in the northern Barents Sea. Meddelelser 135. Pp. 49-57. Oslo: Norwegian Polar Institute.

Jakubas D. \& Wojczulanis-Jakubas K. 2011. Subcolony variation in phenology and breeding parameters in little auk Alle alle. Polar Biology 34, 31-39.

Jakubas D. \& Wojczulanis-Jakubas K. 2014. Consequences of experimental clutch enlargement in a High Arctic single-egg layer, the little auk (Alle alle). Canadian Journal of Zoology 92, 681-687.

Jarvinen A. 1994. Global warming and egg size of birds. Ecography 17, 108-110.

Jørgensen E. \& Blix A.S. 1985. Effects of climate and nutrition on growth and survival of willow ptarmigan chicks. Ornis Scandinavica 16, 99-107.

Kersten M. \& Brenninkmeijer A. 1995. Growth, fledging success and post-fledging survival of juvenile oystercatchers Haematopus ostralegus. Ibis 137, 396-404.

Kesler D.C. \& Haig S.M. 2005. Microclimate and nest-site selection in Micronesian kingfishers. Pacific Science 59, 499-508.

Konarzewski M. \& Taylor J.R. 1989. The influence of weather conditions on growth of little auk Alle alle chicks. Ornis Scandinavica 20, 112-116.

Krijgsveld K.L., Reneerkens J.W., McNett G.D. \& Ricklefs R.E. 2003. Time budgets and body temperatures of American golden-plover chicks in relation to ambient temperature. The Condor 105, 268-278.

Lyon B.E. \& Montgomerie R.D. 1985. Incubation feeding in snow buntings: female manipulation or indirect parental care? Behavioral Ecology and Sociobiology 17, 279-284.
Mallory M.L. \& Forbes M.R. 2011. Nest shelter predicts nesting success but not nesting phenology or parental behaviors in High Arctic northern fulmars Fulmarus glacialis. Journal of Ornithology 152, 119-126.

Manuwal D.A. 1974. The natural history of Cassin's auklet (Ptychoramphus aleuticus). The Condor 76, 421-431.

Maziarz M., Broughton R.K. \& Wesołowski T. 2017. Microclimate in tree cavities and nest-boxes: implications for hole-nesting birds. Forest Ecology and Management 389, 306-313.

Maziarz M. \& Wesołowski T. 2013. Microclimate of tree cavities used by great tits (Parus major) in a primeval forest. Avian Biology Research 6, 47-56.

McComb W.C. \& Noble R.E. 1981. Microclimates of nest boxes and natural cavities in bottomland hardwoods. The Journal of Wildlife Management 45, 284-289.

Mersten-Katz C., Barnea A., Yom-Tov Y. \& Ar A. 2012. The woodpecker's cavity microenvironment: advantageous or restricting? Avian Biology Research 5, 227-237.

Moe B., Stempniewicz L., Jakubas D., Angelier F., Chastel O., Dinessen F., Gabrielsen G.W., Hanssen F., Karnovsky N.J., Ronning B., Welcker J., Wojczulanis-Jakubas K. \& Bech C. 2009. Climate change and phenological responses of two seabird species breeding in the High-Arctic. Marine Ecology Progress Series 393, 235-246.

Morrison K.W., Hipfner J.M., Gjerdrum C. \& Green D.J. 2009. Wing length and mass at fledging predict local juvenile survival and age at first return in tufted puffins. The Condor 111, 433-441.

Newton I. 1978. Feeding and development of sparrowhawk Accipiter nisus nestlings. Journal of Zoology 184, 465-487.

Nilsson J.F., Stjernman M. \& Nilsson J.-Å. 2008. Experimental reduction of incubation temperature affects both nestling and adult blue tits Cyanistes caeruleus. Journal of Avian Biology 39, 553-559.

Osborne J.W. 2010. Improving your data transformations: applying the Box-Cox transformation. Practical Assessment, Research \& Evaluation 15(12), 1-9.

Pyle P., Sydeman W.J. \& Hester M. 2001. Effects of age, breeding experience, mate fidelity and site fidelity on breeding performance in a declining population of Cassin's auklets. Journal of Animal Ecology 70, 1088-1097.

Richards F.J. 1959. A flexible growth function for empirical use. Journal of Experimental Botany 10, 290-301.

Schaaf A.A., García C.G., Puechagut P.B., Silvetti L.E., Tallei E., Ortis F. \& Quaglia A.I. 2018. Effect of geographical latitude and sun exposure on rufous hornero (Furnarius rufus) nest orientation. Journal of Ornithology 4, 967-974.

Sheaier S.E. \& Malecki P.A. 1996. Predicting breeding success of Atlantic population Canada geese from meteorological variables. Journal of Wildlife Management 60, 882-890.

Skinner W.R., Jefferies R.L., Carleton T.J., Rockwell R.F. \& Abraham K.F. 1998. Prediction of reproductive success and failure in lesser snow geese based on early season climatic variables. Global Change Biology 4, 3-16.

Sockman K.W. \& Schwabl H. 1998. Hypothermic tolerance in an embryonic American kestrel (Falco sparverius). Canadian Journal of Zoology 76, 1399-1402.

Steen J.B. \& Gabrielsen G.W. 1986. Thermogenesis in newly hatched eider (Somateria mollissima) and long-tailed duck (Clangula hyemalis) ducklings and barnacle goose (Branta leucopsis) goslings. Polar Research 4, 181-186.

Stempniewicz L. 2001. Alle alle little auk. BWP update. Journal of Birds Western Palearctic 3, 175-201.

Taylor I.R. 1983. Effect of wind on the foraging behaviour of common and Sandwich terns. Ornis Scandinavica 14, 90-96. 
Tazawa H., Okuda A., Nakazawa S. \& Whittow G.C. 1989. Metabolic responses of chicken embryos to graded, prolonged alterations in ambient temperature. Comparative Biochemistry and Physiology 92, 613-617.

Tortosa F.S. \& Castro F. 2003. Development of thermoregulatory ability during ontogeny in the white stork Ciconia ciconia. Ardeola 50, 39-45.

Vermeer K., Vermeer R.A., Summers K.R. \& Billings R.R. 1979. Numbers and habitat selection of Cassin's auklet breeding on Triangle Island, British Columbia. The Auk 96, 143-151.

Visser H.G. 1998. Development of temperature regulation. J. M. Starck \& R.E. Ricklefs (eds.): Avian growth and development. Pp. 117-156. Oxford: Oxford University Press.

Walsberg G.E. 1981. Nest-site selection and the radiative environment of the warbling vireo. The Condor 83, 86-88.
Walsberg G.E. \& King J.R. 1978. The heat budget of incubating mountain white-crowned sparrows (Zonotrichia leucophrys oriantha) in Oregon. Physiological Zoology 51, 92-103.

Wasilewski A. 1986. Ecological aspects of the breeding cycle in the Wilson's storm petrel, Oceanites oceanicus (Kuhl), at King George Island (South Shetland Islands, Antarctica). Polish Polar Research 7, 173-216.

Webb D.R. 1987. Thermal tolerance of avian embryos: a review. The Condor 89, 874-898.

Weimerskirch H. 1992. Reproductive effort in long-lived birds: age-specific patterns of condition, reproduction and survival in the wandering albatross. Oikos 64, 464-473.

Wiebe K.L. 2001. Microclimate of tree cavity nests: is it important for reproductive success in northern flickers? The Auk 118, 412-421. 